\section{RMD Open}

Rheumatic \&

Musculoskeletal Diseases

\title{
Occupational exposure to organic dusts and risk of developing rheumatoid arthritis: findings from a Swedish population-based case-control study
}

To cite: Ilar A, Gustavsson $P$, Wiebert $P$, et al. Occupational exposure to organic dusts and risk of developing rheumatoid arthritis: findings from a Swedish population-based case-control study. RMD Open 2019;5:e001049. doi:10.1136/ rmdopen-2019-001049

- Additional material is published online only. To view please visit the journal online (http://dx.doi.org/10.1136/ rmdopen-2019-001049).

Received 8 July 2019

Revised 4 November 2019

Accepted 7 November 2019

Check for updates

(c) Author(s) (or their employer(s)) 2019. Re-use permitted under CC BY-NC. No commercial re-use. See rights and permissions. Published by BMJ.

${ }^{1}$ Unit of Translational

Epidemiology, The Institute of Environmental Medicine, Karolinska Institutet, Stockholm, Sweden

${ }^{2}$ Unit of Occupational Medicine, The Institute of Environmental Medicine, Karolinska Institutet, Stockholm, Sweden

${ }^{3}$ Centre for Occupational and Environmental Medicine, Stockholm County Council, Stockholm, Sweden

Correspondence to Anna llar; anna.ilar@ki.se

\section{ABSTRACT}

Objectives We estimated the association between occupational exposures to five different organic dusts: wood, animal, paper, textile and flour dust and the risk of developing rheumatoid arthritis (RA).

Methods This population-based case-control study analysed 12582 incident cases and 129335 controls. Participants were identified from national public authority and quality registers. Census data on occupations were collected 1960-2010 and we estimated the exposure to organic dust with the help of job-exposure matrices. We used logistic regression to assess the $\mathrm{OR}$ of seropositive or seronegative RA. Estimates were adjusted for the matching variables (sex, county, age and index year), education and occupational silica exposure.

Results Exposure to animal dust was associated with an increased risk of RA among both men and women. The OR was $1.2(95 \% \mathrm{Cl}=1.1$ to 1.4$)$ for seropositive $\mathrm{RA}$ and $1.3(95 \% \mathrm{Cl}=1.1$ to 1.5$)$ for seronegative RA among ever exposed participants compared with unexposed. The risk increased with duration of exposure for seropositive RA, and participants who had been exposed in five or more censuses had an OR of $1.6(95 \% \mathrm{Cl}=1.1$ to 2.2 , $\mathrm{p}$ for trend $=0.003$ ). Exposure to textile dust also generated a significant dose-response relationship for seropositive RA ( $p$ for trend=0.014). We detected no association between exposure to wood, paper or flour dust and risk of RA. Conclusions Overall, exposure to animal dust and textile dust was associated with an increased risk of developing $R A$. These observations give further support to the notion that airborne exposures are involved in the aetiology of RA.

\section{INTRODUCTION}

There is an increasing amount of evidence suggesting that the lungs play an important role in the aetiology of rheumatoid arthritis (RA). ${ }^{2}$ This hypothesis is confirmed by several airborne exposures being linked to an increased risk of the disease. Cigarette smoking is the main environmental risk factor for RA, and the risk is stronger for the seropositive subtype of the disease. ${ }^{3}{ }^{4}$ Thus, it is of interest to investigate if this is the case also

\section{Key messages}

What is already known about this subject?

- Inorganic dusts have been associated with an increased risk of rheumatoid arthritis (RA), whereas less is known about the association with organic dusts.

What does this study add?

- Animal dust and textile dust are associated with an increased risk of RA.

- For seropositive RA, the risk associated with these exposures increased with increasing duration of the exposure.

How might this impact on clinical practice?

- RA is one of the most prevalent autoimmune diseases worldwide and it is important to find preventable risk factors.

for other airborne exposures. If an airborne exposure does not display this pattern, it speaks in favour of that other mechanisms are involved.

Airborne occupational exposures are prevalent in the construction and production industry, and employment in these industries have been observed to be associated with an increased risk of RA, even after adjustment for potential confounding from smoking. 5 Exposure to the inorganic dusts such as asbestos and silica appears to be two airborne exposures contributing to this observation. $^{6-8}$ Women are much less represented in occupations at risk of being exposed to inorganic dusts, yet 7 out of 10 patients with RA in Sweden are women. ${ }^{9}$ Hence, there is a lack of studies investigating the association between airborne exposures and risk of RA with enough power to stratify findings sex and seropositive status.

As compared with inorganic dusts, the potential association between different types 
of organic dusts and RA has been much less explored. Organic dust can be defined as airborne particles from animals, plants, fungi or bacteria suspended in the air. They are produced through mechanical processes and differ by chemical and physical composition. Workers within certain industries where exposure to organic dust is present have been suggested to have an increased risk of RA, such as farmers and textile workers, ${ }^{10}{ }^{11}$ but there is a need for more research to confirm these findings.

In this study, we aimed to decrease the current knowledge gap between organic dusts and RA. We investigated the relation between exposure to five different types of organic dust (wood, animal, paper, textile and flour dust) and risk of RA among both men and women in a large population-based case-control study.

\section{METHODS}

\section{Identification of cases and controls}

The study base consisted of adults living in Sweden between 1996 and 2013. Incident patients with RA were identified through the Swedish Rheumatology Quality (SRQ) Register, the National Patient Register, the Swedish Prescribed Drug Register and the Swedish case-control study Epidemiological Investigation of Rheumatoid Arthritis (EIRA). From the SRQ Register and the EIRA study, we got information on whether cases were seropositive or seronegative. A seropositive case is a patient with RA who has tested positive for rheumatoid factor (RF) or anti-citrullinated protein antibody (ACPA). We defined patients as incident RA cases if they fulfilled all four criteria beneath:

1. A first-time visit to the inpatient or specialist outpatient care 2006 or later according to the national patient register and with a main or contributory diagnosis of seropositive or seronegative RA, according to the International Statistical Classification of Diseases and Related Health Problems, 10th Revision (M05, M06, M12.3), or been enrolled as an incident patient with RA in SRQ 2006 or later.

2. A second inpatient discharge or specialist outpatient care visit, with a main or contributory diagnosis of seropositive or seronegative RA, within 1 year of the first visit.

3. At least one of the above visits should have taken place at an internal medicine or rheumatology department.

4. Received disease-modifying anti-rheumatic drug treatment (registered for RA) with biologics, nonbiological treatment, gold, prescription non-steroidal anti-inflammatory drugs and glucocorticoids, according to the prescribed drug register.

Ten controls per case were randomly selected from the National Population Register, matched on age, sex, county and index year (the year prior to when cases received their diagnosis). The study was approved by the Regional Stockholm ethics committee.

\section{Definition of exposures}

Sweden has a long tradition of collecting data on the population through censuses. Population and housing censuses were carried out in Sweden between 1960 and 1990 and in which all adults were obliged to fill in a form including information about their housing status, education and occupation. Data on occupation were collected from these censuses every tenth or fifth year. Construction of an occupational register began in 1999 and the Swedish Occupational Register was published in 2003 with data relating to occupational title in 2001. The register is based on data from approximately 20 different sources, collected mainly from employers in connection with the official annual salary statistics or via a survey for smaller companies or organisations. For this specific study, we collected the participants' work titles for the years 1960, 1970, 1975, 1980 and 1990 from the population and housing censuses and for 2001 and 2010 from register data from Statistics Sweden.

We assessed exposure to five types of organic dusts prior to study inclusion by applying a Swedish job-exposure matrix (JEM) to the work history collected for each study participant. ${ }^{12} 13$ The JEM was developed to estimate exposure for the time period 1955 until 2014. The matrix specified the probability of exposure and the air concentration of occupational exposure expressed as the 8-hour time-weighted average of exposure to wood dust, animal dust, paper dust, textile dust and flour dust.

Wood dust was defined as occupational exposure to inhalable wood dust (pine, spruce, birch, other softwoods and hardwoods, cane, wood bark, etc). Animal dust was defined as occupational, inhalable exposure to dust from living animals (cows, horses, cats, dogs, reindeer, etc), or hairs of animals (raw wool, furs of minks, foxes, etc) and did not include treated wool dust, raw cotton or leather dust. Paper dust was defined as occupational, inhalable exposure to pulp or paper dust (pulp, newsprint, printing paper, soft papers, cardboard, etc). Textile dust was defined as occupational, inhalable exposure to dust from treated cotton, treated wool or other treated natural materials used in fabrics, other textiles or garments. It did not include raw cotton, raw wool or synthetic textiles. Flour dust was defined as occupational, inhalable exposure to flour dust (from wheat, oat, barley and rye), milk powder, potato powder, starch powder or fish powder.

\section{Statistical analysis and confounders}

13120 cases and 136359 controls were enrolled from the five sources of data and were identified in at least one of the censuses. Of these individuals, 181 were excluded from the analysis because of inaccurate information on occupation or personal identity number in the censuses and 7022 were excluded since work title was missing or unidentifiable in all seven censuses. Information on education was missing for 359 persons and these were excluded from the analysis, resulting in 12582 cases and 
129335 controls with complete information on all variables in the final analysis.

We performed unconditional logistic regression analysis to calculate ORs and 95\% CIs for the association between exposure to each of the five different types of organic dusts prior to study inclusion and risk of developing RA, versus workers never exposed to each organic dust. Findings were stratified by sex and seropositive status. In the analysis, we restricted the exposed group of workers to those who had reported at least one occupation where the probability of exposure was at least $50 \%$ for the organic dust type in question. This was done to restrict the analysis to workers with a high probability of exposure.

The number of censuses in which exposure occurred was used as a proxy for duration of exposure. We divided number of censuses exposed into three groups: 1-2 censuses, 3-4 censuses or 5-7 censuses versus unexposed workers. The highest intensity of exposure was assessed from the occupation with the highest 8-hour time-weighted average of exposure. For highest intensity, we divided exposed workers into three exposure groups where the cut-off was set at median ( $\leq 50$ th percentile), the third quartile $(>50-\leq 75$ th percentile) and above the third quartile ( $>75$ th percentile) based on exposed controls, versus unexposed workers. We performed tests for trend in the logistic regression analysis by treating the number of occupations exposed to organic dusts or exposure to highest intensity as a continuous variable. P-values $<0.05$ were considered statistically significant.

All analyses were adjusted for the matching variables age, sex, county and index year. In addition, we considered potential confounding from occupational silica exposure and education. Estimates for silica came from the same JEM as described above. Highest educational level achieved at baseline was collected from the Swedish Register of Education. We analysed $\leq 9$ years, 10-12 years versus $>12$ years of education. If register data on education were missing, but reported in the EIRA study, we used this information instead.

Of the 142276 participants (with or without information on education), $23 \%$ of cases and $4 \%$ of controls had full information on the two known confounders smoking and alcohol consumption, collected from a questionnaire sent out to the EIRA study participants. As supplementary material, we provide online supplementary tables S1-S4, where we have imputed the missing values for alcohol use and smoking by generating 15 imputed datasets with the PROC MI command in SAS. These datasets were analysed and thereafter the results were pooled using the command PROC MIANALYZE. Alcohol was defined as high (above 75th percentile), moderate (above median to the 75 th percentile) or no consumption versus low (zero to median) consumption of alcohol, based on drinks consumed per week prior to the index year (for a more detailed definition, see Ilar et al). ${ }^{5}$ Smoking was assessed as pack-years. One pack-year was defined as 20 cigarettes smoked per day for 1 year. It was treated as a continuous variable with never smokers as the reference group. Quadratic terms for the continuous variable age (and smoking in the multiple imputation analysis) were added to the model to allow for non-linearity.

All analyses were performed using SAS V. 9.4.

\section{RESULTS}

12582 cases and 129335 controls were included in the analysis. A presentation of the most common occupations by organic dust type, census year and sex are presented in online supplementary table S5.

The distribution of sociodemographic characteristics and exposure to organic dusts is presented in table 1 . A higher proportion of men than women had been exposed to wood, animal, paper and flour dust, whereas women were more likely to be exposed to textile dust. The likelihood of being exposed to several different types of dusts was in general relatively small.

Table 1 Table of characteristics $(n=141917)$

\begin{tabular}{|c|c|c|c|c|}
\hline & \multicolumn{2}{|l|}{ Men } & \multicolumn{2}{|l|}{ Women } \\
\hline & Cases & Controls & Cases & Controls \\
\hline & $(n=3923)$ & $(n=40142)$ & $(n=8659)$ & $(n=89193)$ \\
\hline Age (median) & 61 & 61 & 57 & 57 \\
\hline Exposed to wood dust (\%) & $396(10)$ & $3462(9)$ & $78(1)$ & $643(1)$ \\
\hline Exposed to animal dust (\%) & $209(5)$ & $1674(4)$ & 207 (2) & $1696(2)$ \\
\hline Exposed to paper dust (\%) & $241(6)$ & $2564(6)$ & $377(4)$ & $3480(4)$ \\
\hline Exposed to textile dust (\%) & $60(2)$ & 469 (1) & $317(4)$ & $2765(3)$ \\
\hline Exposed to flour dust (\%) & $46(1)$ & $365(1)$ & $32(0)$ & $368(0)$ \\
\hline \multicolumn{5}{|l|}{ Education (\%) } \\
\hline 9 years or less & $1412(36)$ & $12374(31)$ & $2157(25)$ & $20288(23)$ \\
\hline $10-12$ years & $1735(44)$ & $17492(44)$ & $3991(46)$ & $39562(44)$ \\
\hline$>12$ years & $776(20)$ & $10276(26)$ & $2511(29)$ & $29343(33)$ \\
\hline
\end{tabular}


In table 2, we present the association between exposure to the five different types of organic dusts and the risk of developing RA. We observed an association between animal dust, wood dust and textile dust for overall RA among men and women combined when adjusting for the matching variables age, sex, county and index year. When additionally adjusting for potential confounding from education level and silica exposure, increased risks were observed for workers exposed to animal dust and textile dust compared with unexposed workers. With regard to seropositive RA, men exposed to animal dust had an OR of 1.3 (95\% CI 1.1 to 1.6), and for women the corresponding OR was 1.1 (95\% CI 1.0 to 1.4). For seronegative RA, no significant associations were observed among men. Among women, an association between exposure to animal dust and risk of seronegative RA was observed (OR 1.4 (95\% CI 1.1 to 1.8).

We proceeded to explore whether there was an exposure-response relation between duration of exposure to organic dust and risk of developing RA, using number of censuses with exposure as a proxy for exposure duration (table 3). Because a low number of workers had been exposed to organic dusts in several censuses, we present the results among men and women combined. We observed statistically significant dose-response relations regarding exposure to animal dust for both seropositive RA and seronegative RA, respectively. For seropositive RA, the OR for persons with the longest duration of exposure ( $>45$ years of exposure) was 1.6 (95\% CI 1.1 to 2.2, $\mathrm{p}$ for trend=0.003). For the seronegative subtype, the corresponding OR was $1.3(95 \% \mathrm{CI}=0.8$ to 2.0 , $\mathrm{p}$ for trend $=0.016$ ). Also, for textile dust we observed a significant dose-response relation in relation to seropositive RA ( $\mathrm{p}$ for trend=0.014).

In table 4 , we investigated the risk of RA by highest intensity in men and women combined. As was noted for duration of exposure, animal dust was the dust type most strongly associated with an increased risk of mainly seropositive RA. Workers exposed to highest category of exposure intensity of animal dust $\left(>0.07 \mathrm{mg} / \mathrm{m}^{3}\right)$ had an adjusted OR of 1.4 (95\% CI=1.1 to 1.8$)$. We did not observe any dose-response relation between intensity of exposure to organic dusts and risk of RA.

\section{DISCUSSION}

In this study, we explored the association between occupational exposure to five different organic dusts and risk of developing RA. The main finding was that both males and females occupationally exposed to animal dust were associated with an increased risk of developing RA. For seropositive RA, this risk increased with longer duration and/or higher intensity of exposure. Among the five organic dusts investigated in this study, animal dust and textile dust have previously been discussed in relation to the risk of developing RA. Epidemiological studies have suggested an association between RA risk and either exposure to animal dust ${ }^{14}$ or farm work. ${ }^{10}{ }^{14-17}$
We observed an increased risk of seropositive RA among workers with the highest intensity of exposure to animal dust $(\mathrm{OR}=1.4,95 \% \mathrm{CI}=1.1$ to 1.8$)$. The mean highest intensity value in this group was $0.19 \mathrm{mg} / \mathrm{m}^{3}$, though there is no occupational exposure limit for animal dust in Sweden to compare this number with. One could argue that it is more likely that the risk increases with duration rather than with intensity, given the significant trend for exposure-response we observed in table 3. In addition, there was an increase with increasing duration for seropositive RA, despite the fact that the mean average intensity of exposure was similar in the three groups of exposure duration. Similarly, research on smoking has shown that it is the time a person has smoked rather than the number of cigarettes smoked that is associated with an increased risk. ${ }^{18-21}$

With regard to our observation of an association between animal dust and risk of developing RA, it should be kept in mind that many of the occupations involving contact with animals also are exposed to other potentially harmful agents, such as pesticides or grain dust for instance. Apart from animal dust, the association between agricultural work and RA has also been proposed to be related to exposure to fertilisers or solvents. ${ }^{22}{ }^{23} \mathrm{We}$ did not consider these exposure in our findings. A recent animal study has, however, shown that inhalation to organic dust exposure from swine confinement feeding facilities led to airway inflammation and arthritis among male mice. ${ }^{24}$

We also found that occupational exposure to textile dust was associated with an increased risk of seropositive RA, which showed a significant trend with duration of exposure. An association between self-reported textile dust exposure and risk of RA has been reported among women in Malaysia. ${ }^{11}$ Associations were observed both for ACPA+RAand ACPA-RA, and the OR for overall RA was $2.8(95 \% \mathrm{CI}=1.6$ to 5.2$)$. This is in contrast to our study and other studies exploring occupational exposure to textile dust, where either no association or a modest association have been observed. ${ }^{51415}$ The Swedish Work Environment Act has for many decades regulated the work safety in Sweden, and the awareness of harmful exposures among employers and employees in Sweden should be considered comparatively strong. This, together with the downsizing of the textile industry in our part of the world should be borne in mind when comparing results with other parts of the world, as, for instance, to a Malaysian setting. Hence, it is likely that the intensity levels and the cumulative dose of textile exposure are much lower in our study population in relation to the circumstances in Malaysia. A potential underlying mechanism for the association between textile dust exposure and risk of RA might be bacterial endotoxins, which have been shown to active an autoimmune response by causing an inflammation in the lungs. ${ }^{25-27}$

Our study has several advantages over previous ones that sought to compare different types of organic dusts and risk of developing RA. To our knowledge, it is the 


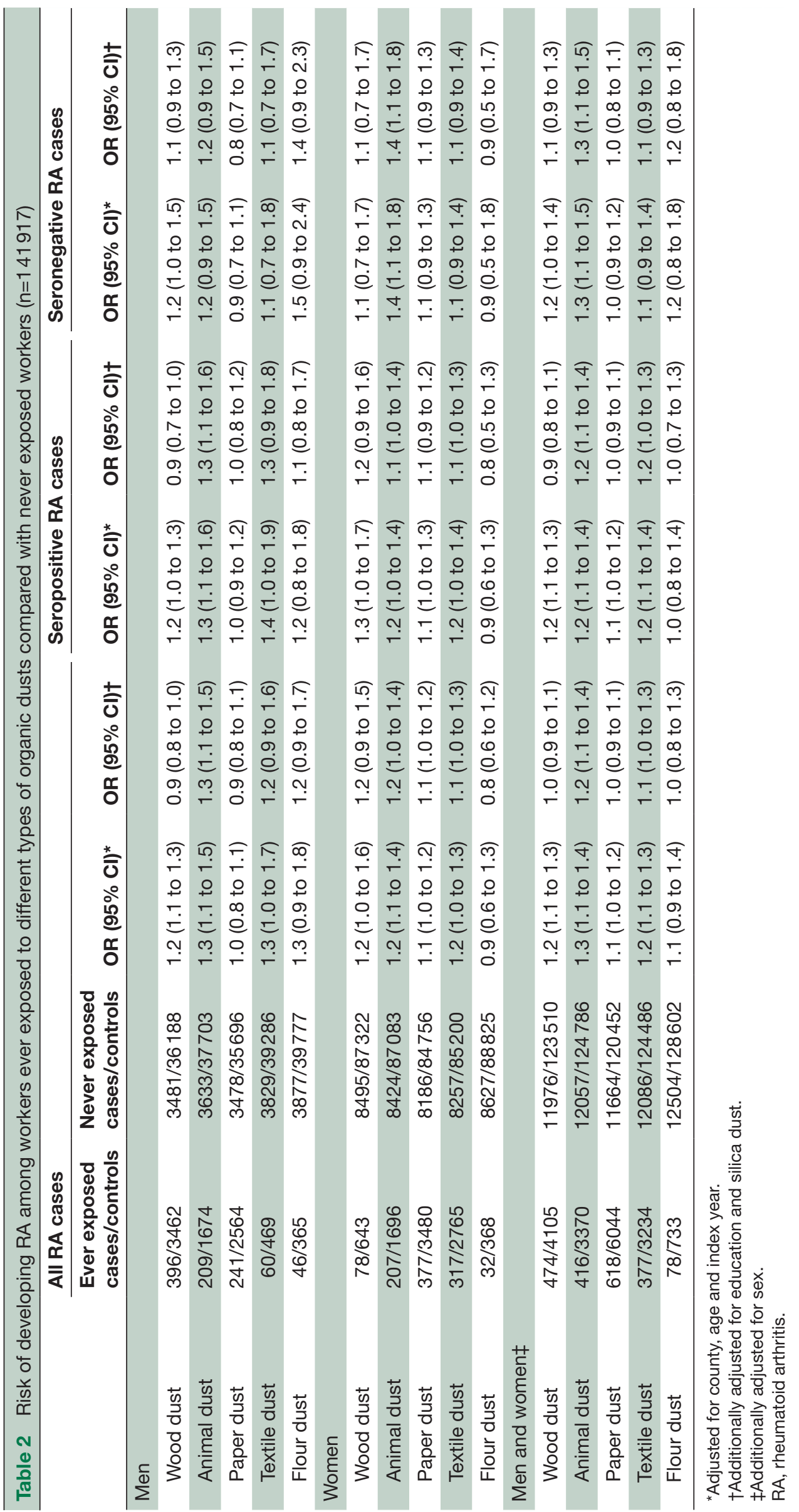


Table 3 Risk of developing RA among workers exposed to organic dust in different number of censuses compared with never exposed workers $(n=141917)$

largest study of its kind to compare organic dust types and risk of RA using incident cases of RA. We were able to stratify most of our findings on sex and RA subtypes which has not been done previously. The rationale for performing the analysis by RA subgroup is that the most established environmental risk factor for RA, smoking, is mainly related to seropositive RA. There are also mechanistic theories why this is the case and what is happening
Seropositive RA RA

Seronegative

Median years

since last

Mean average occupation

intensity (mg/ classified as

exposed OR $(95 \% \mathrm{Cl})^{*} \quad$ OR $(95 \% \mathrm{Cl})^{*} \quad$ OR $(95 \% \mathrm{Cl})^{*}$

\begin{tabular}{|c|c|c|c|c|c|c|}
\hline \multirow{2}{*}{\multicolumn{7}{|c|}{ Wood dust }} \\
\hline & & & & & & \\
\hline Unexposed & \multicolumn{3}{|l|}{$11976 / 123510$} & 1.0 & 1.0 & 1.0 \\
\hline $1-2$ censuses & $304 / 2875$ & 0.84 & 23 & 0.9 (0.8 to 1.0$)$ & 0.9 (0.8 to 1.0$)$ & 1.0 (0.8 to 1.2$)$ \\
\hline 3-4 censuses & $137 / 949$ & 0.73 & 16 & 1.1 (0.9 to 1.4$)$ & 1.1 (0.9 to 1.4$)$ & 1.3 (1.0 to 1.8$)$ \\
\hline 5-7 censuses & $33 / 281$ & 0.76 & 8 & 0.9 (0.7 to 1.4$)$ & 1.0 (0.7 to 1.5$)$ & 0.8 (0.4 to 1.6$)$ \\
\hline$P$ value for trend & & & & 0.966 & 0.747 & 0.555 \\
\hline \multicolumn{7}{|l|}{ Animal dust } \\
\hline Unexposed & \multicolumn{2}{|l|}{$12057 / 124786$} & & 1.0 & 1.0 & 1.0 \\
\hline $1-2$ censuses & $247 / 2054$ & 0.04 & 23 & $1.2(1.1$ to 1.4$)$ & 1.2 (1.0 to 1.4$)$ & 1.3 (1.0 to 1.6$)$ \\
\hline 3-4 censuses & $112 / 911$ & 0.03 & 18 & $1.2(1.0$ to 1.5$)$ & $1.2(0.9$ to 1.5$)$ & 1.4 (1.0 to 1.9$)$ \\
\hline 5-7 censuses & $57 / 405$ & 0.03 & 12 & 1.5 (1.1 to 1.9$)$ & 1.6 (1.1 to 2.2$)$ & 1.3 (0.8 to 2.0 ) \\
\hline $\mathrm{P}$ value for trend & & & & 0.000 & 0.003 & 0.016 \\
\hline \multicolumn{7}{|l|}{ Paper dust } \\
\hline Unexposed & \multicolumn{2}{|l|}{$11664 / 120452$} & & 1.0 & 1.0 & 1.0 \\
\hline $1-2$ censuses & $502 / 4929$ & 0.10 & 21 & $1.0(0.9$ to 1.1$)$ & 1.0 (0.9 to 1.1$)$ & 1.0 (0.8 to 1.2$)$ \\
\hline 3-4 censuses & 96/893 & 0.12 & 15 & 1.1 (0.9 to 1.3$)$ & 1.1 (0.9 to 1.5$)$ & 0.9 (0.6 to 1.4$)$ \\
\hline 5-7 censuses & $20 / 222$ & 0.09 & 8 & 0.9 (0.6 to 1.5$)$ & 1.0 (0.6 to 1.7$)$ & 0.8 (0.4 to 1.8$)$ \\
\hline$P$ value for trend & & & & 0.760 & 0.411 & 0.501 \\
\hline \multicolumn{7}{|l|}{ Textile dust } \\
\hline Unexposed & \multicolumn{2}{|l|}{$12086 / 124486$} & & 1.0 & 1.0 & 1.0 \\
\hline $1-2$ censuses & $314 / 2740$ & 0.14 & 32 & 1.1 (1.0 to 1.3 ) & 1.1 (1.0 to 1.3 ) & 1.1 (0.9 to 1.3$)$ \\
\hline 3-4 censuses & $55 / 428$ & 0.13 & 21 & $1.2(0.9$ to 1.6$)$ & $1.2(0.9$ to 1.7$)$ & 1.2 (0.7 to 2.0 ) \\
\hline 5-7 censuses & $8 / 66$ & 0.13 & 15 & $1.2(0.6$ to 2.5$)$ & $1.3(0.6$ to 3.1$)$ & - \\
\hline$P$ value for trend & & & & 0.021 & 0.014 & 0.564 \\
\hline \multicolumn{7}{|l|}{ Flour dust } \\
\hline Unexposed & \multicolumn{2}{|l|}{$12504 / 128602$} & & 1.0 & 1.0 & 1.0 \\
\hline $1-2$ censuses & $62 / 617$ & 1.13 & 26 & 1.0 (0.8 to 1.3$)$ & 0.9 (0.7 to 1.3$)$ & 1.1 (0.7 to 1.7$)$ \\
\hline 3-4 censuses & $12 / 81$ & 1.21 & 18 & 1.4 (0.8 to 2.7$)$ & $1.6(0.8$ to 3.2$)$ & - \\
\hline 5-7 censuses & $4 / 35$ & 1.21 & 14 & - & - & - \\
\hline$P$ value for trend & & & & 0.256 & 0.637 & 0.186 \\
\hline
\end{tabular}

*Adjusted for county, age, sex, index year, education and silica dust.

$\mathrm{RA}$, rheumatoid arthritis. in the lungs to initiate a process that later may lead to

Another advantage is that we identified all cases that are known to the healthcare system (which is known to have a high coverage and accuracy) together with randomly selected matched population controls and the number of excluded subjects was small. Thus, bias due to selection will be very limited. We further adjusted seropositive RA. ${ }^{28}$ 
Table 4 Risk of developing RA among workers exposed to organic dust from highest intensity compared with never exposed workers $(n=141917)$

\begin{tabular}{|c|c|c|c|c|c|c|}
\hline \multirow[b]{2}{*}{ Percentiles } & \multicolumn{4}{|l|}{ All RA cases } & \multirow[b]{2}{*}{$\begin{array}{l}\text { Seropositive RA } \\
\text { OR }(95 \% \mathrm{Cl})^{\star}\end{array}$} & \multirow{2}{*}{$\begin{array}{l}\text { Seronegative } \\
\text { RA } \\
\\
\text { OR }(95 \% \mathrm{Cl})^{*}\end{array}$} \\
\hline & Cases/controls & $\begin{array}{l}\text { Mean highest } \\
\text { intensity (mg/ } \\
\mathrm{m}^{3} \text { ) }\end{array}$ & $\begin{array}{l}\text { Median years } \\
\text { since last } \\
\text { occupation } \\
\text { classified as } \\
\text { exposed }\end{array}$ & OR $(95 \% \mathrm{Cl})^{*}$ & & \\
\hline \multicolumn{7}{|l|}{ Wood dust } \\
\hline Unexposed & $11971 / 123458$ & & & 1.0 & 1.0 & 1.0 \\
\hline$\leq 50$ & $275 / 2071$ & 0.44 & 25 & 1.1 (0.9 to 1.2$)$ & 1.0 (0.9 to 1.2$)$ & 1.2 (1.0 to 1.6$)$ \\
\hline$>50-\leq 75$ & $121 / 1192$ & 1.24 & 11 & 0.9 (0.7 to 1.1$)$ & 0.9 (0.7 to 1.1$)$ & 0.9 (0.7 to 1.3$)$ \\
\hline$>75$ & $83 / 894$ & 1.78 & 21 & 0.9 (0.7 to 1.1$)$ & 0.9 (0.7 to 1.1$)$ & 0.8 (0.6 to 1.2$)$ \\
\hline$P$ value for trend & & & & 0.206 & 0.203 & 0.678 \\
\hline \multicolumn{7}{|l|}{ Animal dust } \\
\hline Unexposed & $12053 / 124728$ & & & 1.0 & 1.0 & 1.0 \\
\hline$\leq 50$ & $175 / 1454$ & 0.01 & 22 & $1.2(1.0$ to 1.4$)$ & 1.1 (0.9 to 1.4$)$ & 1.4 (1.1 to 1.7$)$ \\
\hline$>50-\leq 75$ & $136 / 1132$ & 0.02 & 24 & 1.2 (1.0 to 1.4$)$ & 1.1 (0.9 to 1.4$)$ & 1.3 (1.0 to 1.8$)$ \\
\hline$>75$ & $109 / 842$ & 0.19 & 13 & 1.3 (1.1 to 1.6$)$ & 1.4 (1.1 to 1.8$)$ & 1.1 (0.7 to 1.6$)$ \\
\hline$P$ value for trend & & & & 0.114 & 0.082 & 0.758 \\
\hline \multicolumn{7}{|l|}{ Paper dust } \\
\hline Unexposed & $11650 / 120347$ & & & 1.0 & 1.0 & 1.0 \\
\hline$\leq 50$ & $311 / 3174$ & 0.05 & 20 & 1.0 (0.9 to 1.1$)$ & $1.0(0.8$ to 1.1$)$ & 0.9 (0.8 to 1.2$)$ \\
\hline$>50-\leq 75$ & $153 / 1501$ & 0.09 & 15 & 1.1 (0.9 to 1.3 ) & 1.0 (0.8 to 1.2$)$ & 1.2 (0.9 to 1.5$)$ \\
\hline$>75$ & $168 / 1474$ & 0.28 & 23 & 1.1 (1.0 to 1.3 ) & 1.2 (1.0 to 1.5$)$ & 0.9 (0.6 to 1.2$)$ \\
\hline$P$ value for trend & & & & 0.659 & 0.377 & 0.591 \\
\hline \multicolumn{7}{|l|}{ Textile dust } \\
\hline Unexposed & $12081 / 124455$ & & & 1.0 & 1.0 & 1.0 \\
\hline$\leq 50$ & $273 / 2280$ & 0.11 & 30 & 1.2 (1.0 to 1.3$)$ & $1.2(1.0$ to 1.4$)$ & $1.2(0.9$ to 1.4$)$ \\
\hline$>50-\leq 75$ & $22 / 241$ & 0.20 & 39 & 0.9 (0.6 to 1.4$)$ & 1.0 (0.6 to 1.6$)$ & 0.8 (0.3 to 1.7$)$ \\
\hline$>75$ & $87 / 744$ & 0.25 & 30 & 1.1 (0.9 to 1.4$)$ & 1.2 (0.9 to 1.5$)$ & 1.1 (0.7 to 1.6$)$ \\
\hline $\mathrm{P}$ for trend & & & & 0.099 & 0.066 & 0.779 \\
\hline \multicolumn{7}{|l|}{ Flour dust } \\
\hline Unexposed & $12503 / 128587$ & & & 1.0 & 1.0 & 1.0 \\
\hline$\leq 50$ & 79/748 & 1.17 & 24 & 1.0 (0.8 to 1.3$)$ & 1.0 (0.7 to 1.3$)$ & 1.2 (0.8 to 1.7$)$ \\
\hline$>50-\leq 75$ & $0 / 0$ & - & - & - & - & - \\
\hline$>75$ & $0 / 0$ & - & - & - & - & - \\
\hline $\mathrm{P}$ value for trend & & & & 0.538 & 0.756 & 0.499 \\
\hline
\end{tabular}

*Adjusted for county, age, sex, index year, education and silica dust.

RA, rheumatoid arthritis.

our main findings for silica dust, which is considered the strongest occupational risk factor of RA so far. ${ }^{69} \mathrm{We}$ used register data on highest educational level as a proxy for lifestyle-related confounders, such as smoking and alcohol. Almost all participants had data on education $(99.7 \%)$. As shown in the online supplementary tables S1-S4, adjusting for confounding from cigarette smoking and alcohol with imputed data showed similar results as adjusting for education. Few studies on occupation or occupational exposures have attempted to adjust for smoking or other potential harmful exposures in the work environment. ${ }^{510}$

Using a JEM is advantageous in situations when the study population is large and where measuring occupational exposure for each study participant is not feasible. Since a JEM was used to classify the exposures of interest, there is no risk of differential misclassification of the exposure between cases and controls. The disadvantage 
of using a JEM is that all workers in some occupations are classified as exposed, even if not all are truly exposed. This will introduce non-differential misclassification of the exposure, which likely will bias the strengths of the studied associations toward the null value. The observation of a dose-response relation between duration of exposure to animal dust and textile dust and risk of RA provides support for that these findings are correct. Finally, one should keep in mind that the definitions of organic dust types may vary in different JEMs, which may have an impact on comparability of research findings.

Use of protective equipment and good workplace routines can affect exposure levels. Normally larger companies are better at promoting a safe work environment than smaller companies, which can affect exposure. Similarly, stationary workplaces usually have better opportunities to create good conditions for a safe work environment compared with work in the construction industry. Individual factors can also be of great importance, for example the variation associated with working methods and the awareness of risks. These factors may give rise to some misclassification of the exposure, but it seems unlikely that it would be so systematic that it would distort the results for either animal dust or textile dust.

In conclusion, in this register-based study from Sweden, the ORs between exposure to organic dust and RA risk was overall low. Nevertheless, our study observed an association between exposure to animal dust and risk of developing RA among both men and women, and an association between exposure to textile dust and risk of seropositive RA among women. Together with previously observed associations between airborne exposures, such as smoking and occupational exposure to silica, asbestos and textile dust, our observation that animal dust and textile dust are associated with increased risk of RA provide further support to the notion of the involvement of the lung in the aetiology of RA.

Contributors Al had full access to all the data used for the analysis in this study and takes full responsibility for the integrity of the data and the accuracy of the data analysis. Study concept and design: Al, LA and PG. Acquisition of data: Al, LA and PW. Statistical analysis: Al. Analysis and interpretation of data: all authors. Drafting of manuscript: Al. Critical revision of manuscript and final approval given: all authors.

Funding The present study was supported by grants from the Swedish Research Council for Health, Working Life and Welfare (grant no: 2013-0194) and AFA Insurance (grant no: 120299).

Competing interests LA have for the EIRA study been supported by research grants from the Swedish Medical Research Council; the Swedish Council for Health, Working Life and Welfare; King Gustaf V:s 80-year foundation; the Swedish Rheumatism Foundation; Stockholm County Council; the insurance company AFA Insurance and the IMI-supported RTCure projects, unrelated to the submitted work. PW has received research grants from AFA Insurance, unrelated to the submitted work. PG has received research grants from the Swedish Research Council for Health, Working Life and Welfare, unrelated to the submitted work. LA received grants from the Swedish Research Council for Health, Working Life and Welfare (grant no: 2013-0194) and AFA Insurance (grant number 120299) to support the present study.

Patient consent for publication Not required.

Ethical approval Ethical approval for the linkage between the National Patient Register, the Swedish Rheumatology Register, the Swedish Prescribed Drug Register, the national population register and the EIRA study was granted by the regional Stockholm ethics committee (Dnr 2009/2005-31/3 and Dnr 2010/93932). Ethical approval for the EIRA study was granted by the ethics committee at Karolinska Institutet and the Regional Stockholm ethics committee (Dnr 96-174 and Dnr 2006/476-31/4).

Provenance and peer review Not commissioned; externally peer reviewed.

Data availability statement No data are available.

Open access This is an open access article distributed in accordance with the Creative Commons Attribution Non Commercial (CC BY-NC 4.0) license, which permits others to distribute, remix, adapt, build upon this work non-commercially, and license their derivative works on different terms, provided the original work is properly cited, appropriate credit is given, any changes made indicated, and the use is non-commercial. See: http://creativecommons.org/licenses/by-nc/4.0/.

ORCID iDs

Anna llar http://orcid.org/0000-0003-0139-1405

Per Gustavsson http://orcid.org/0000-0003-2221-8599

Pernilla Wiebert http://orcid.org/0000-0002-6367-0701

Lars Alfredsson http://orcid.org/0000-0003-1688-6697

\section{REFERENCES}

1 Catrina Al, Joshua V, Klareskog L, et al. Mechanisms involved in triggering rheumatoid arthritis. Immunol Rev 2016;269:162-74.

2 Klareskog L, Catrina Al. Autoimmunity: lungs and citrullination. Nat Rev Rheumatol 2015;11:261-2.

3 Di Giuseppe D, Discacciati A, Orsini N, et al. Cigarette smoking and risk of rheumatoid arthritis: a dose-response meta-analysis. Arthritis Res Ther 2014;16:R61.

4 Källberg H, Ding B, Padyukov L, et al. Smoking is a major preventable risk factor for rheumatoid arthritis: estimations of risks after various exposures to cigarette smoke. Ann Rheum Dis 2011;70:508-11.

5 llar A, Alfredsson L, Wiebert P, et al. Occupation and risk of developing rheumatoid arthritis: results from a population-based case-control study. Arthritis Care Res 2018;70:499-509.

6 Blanc PD, Järvholm B, Torén K. Prospective risk of rheumatologic disease associated with occupational exposure in a cohort of male construction workers. Am J Med 2015;128:1094-101.

7 Stolt $\mathrm{P}$, Yahya A, Bengtsson $\mathrm{C}$, et al. Silica exposure among male current smokers is associated with a high risk of developing ACPApositive rheumatoid arthritis. Ann Rheum Dis 2010;69:1072-6.

$8 \operatorname{llar}$ A, Klareskog L, Saevarsdottir S, et al. Occupational exposure to asbestos and silica and risk of developing rheumatoid arthritis: findings from a Swedish population-based case-control study. RMD Open 2019;5:e000978.

9 Neovius M, Simard JF, Askling J, et al. Nationwide prevalence of rheumatoid arthritis and penetration of disease-modifying drugs in Sweden. Ann Rheum Dis 2011;70:624-9.

10 Olsson AR, Skogh T, Axelson O, et al. Occupations and exposures in the work environment as determinants for rheumatoid arthritis. Occup Environ Med 2004;61:233-8.

11 Too CL, Muhamad NA, Ilar A, et al. Occupational exposure to textile dust increases the risk of rheumatoid arthritis: results from a Malaysian population-based case-control study. Ann Rheum Dis 2016;75:997-1002.

12 Kauppinen T, Heikkilä P, Plato N, et al. Construction of job-exposure matrices for the Nordic occupational cancer study (NOCCA). Acta Oncol 2009;48:791-800.

13 Wiebert P, Lönn M, Fremling K, et al. Occupational exposure to particles and incidence of acute myocardial infarction and other ischaemic heart disease. Occup Environ Med 2012;69:651-7.

14 Gold LS, Ward MH, Dosemeci M, et al. Systemic autoimmune disease mortality and occupational exposures. Arthritis Rheum 2007;56:3189-201

15 Li X, Sundquist J, Sundquist K. Socioeconomic and occupational risk factors for rheumatoid arthritis: a nationwide study based on hospitalizations in Sweden. J Rheumatol 2008;35:986-91.

16 Lundberg I, Alfredsson L, Plato N, et al. Occupation, Occupational Exposure to Chemicals and Rheumatological Disease: $A$ register based cohort study. Scand J Rheumatol 1994;23:305-10.

17 Cooper GS, Miller FW, Germolec DR. Occupational exposures and autoimmune diseases. Int Immunopharmacol 2002;2:303-13.

18 Costenbader KH, Feskanich D, Mandl LA, et al. Smoking intensity, duration, and cessation, and the risk of rheumatoid arthritis in women. Am J Med 2006;119:503.e1-503.e9.

19 Hedström AK, Stawiarz L, Klareskog L, et al. Smoking and susceptibility to rheumatoid arthritis in a Swedish population-based case-control study. Eur J Epidemiol 2018;33:415-23. 
20 Karlson EW, Lee I-M, Cook NR, et al. A retrospective cohort study of cigarette smoking and risk of rheumatoid arthritis in female health professionals. Arthritis \& Rheumatism 1999;42:910-7.

21 Stolt Pet al. Quantification of the influence of cigarette smoking on rheumatoid arthritis: results from a population based case-control study, using incident cases. Ann Rheum Dis 2003;62:835-41.

22 Parks CG, Meyer A, Beane Freeman LE, et al. Farming tasks and the development of rheumatoid arthritis in the agricultural health study. Occup Environ Med 2019;76:243-9.

23 Parks CG, Hoppin JA, De Roos AJ, et al. Rheumatoid arthritis in agricultural health study spouses: associations with pesticides and other farm exposures. Environ Health Perspect 2016;124:1728-34.

24 Poole JA, Thiele GM, Janike K, et al. Combined Collagen-Induced arthritis and organic Dust-Induced airway inflammation to model inflammatory lung disease in rheumatoid arthritis. J Bone Miner Res 2019;34:1733-43.

25 Lai PS, Christiani DC. Long-Term respiratory health effects in textile workers. Curr Opin Pulm Med 2013;19:152-7.

26 Rylander R. Endotoxin and occupational airway disease. Curr Opin Allergy Clin Immunol 2006;6:62-6.

27 Thorn J. The inflammatory response in humans after inhalation of bacterial endotoxin: a review. Inflamm Res 2001;50:254-61.

28 Klareskog L, Stolt P, Lundberg K, et al. A new model for an etiology of rheumatoid arthritis: Smoking may trigger HLA-DR (shared epitope)-restricted immune reactions to autoantigens modified by citrullination. Arthritis Rheum 2006;54:38-46.

29 Stolt Pet al. Silica exposure is associated with increased risk of developing rheumatoid arthritis: results from the Swedish EIRA study. Ann Rheum Dis 2005;64:582-6. 